\title{
University collaboration for co-designing sustainable urban areas
}

\author{
Peter $\breve{C a j k a}^{1 *}$, Veronica Grebennikova ${ }^{2,3}$, Hoang Manh Trung $\mathrm{Vu}^{4}$, and Van Tran $\mathrm{Ngo}^{4}$ \\ ${ }^{1}$ College of International and Public Relations Prague, Department of International Relations and \\ Diplomacy, U Santošky 17, Praha 5, 15000 Prague, Czech Republic \\ ${ }^{2}$ Kuban State University, 149 Stavropolskaya str., Krasnodar, 350040, Russian Federation \\ ${ }^{3}$ Griboyedov Institute of International Law and Economics (IMPE named after A. S. Griboyedov), 21 \\ Entuziastov highway, Moscow, 111024, Russian Federation \\ ${ }^{4}$ National Academy of Public Administration, 201 Phan Boi Chau st., Hue city, Thua Thien Hue \\ province, Vietnam
}

\begin{abstract}
Our article tackles the timely and important issue of the university collaboration aimed at shaping up the sustainable urban areas and contributing to their development through the teaching and research. Universities provided qualified labour force, yield novel research solutions and act as hubs for entrepreneurial activity in urban areas. In this article, we show that even though most of the universities are concentrated in large urban centres and capital regions, many of them are located in small rural areas and have a profound effect on them. We also demonstrate the impact of universities on the sustainable development which is done through the sustainable education as well as the R\&D approaches. These effects are very relevant for the co-designing of sustainable rural areas that can follow the principles of the United Nations' Sustainable Development Goals and the green policies imposed by the majority of the local and central governments around the world.
\end{abstract}

Keywords: sustainability, urban and rural areas, university cooperation.

\section{Introduction}

Universities worldwide tend to establish partnerships in order to recognize that the only viable path to sustainability is to address several aspects of the complex social, economic, technological, political and cultural fabric that surrounds us and to mobilize the necessary institutions, knowledge and resources within a comprehensive framework [1,2]. As more universities and faculties are encouraged to join together for the transition to urban sustainability alliances, several barriers must be overcome. The call of academic functions "co-creation" or "new" is not entirely correct. They include the creation of new technological prototypes, business and new socio-technical systems, as well as the transformation of builtup and natural environments $[3,4]$. Specific transformative changes are needed, whether in the context of protection of small-scale food fisheries, construction of housing for people in urban areas or management of different dry areas in Tibet or Sub-Saharan Africa [5].

\footnotetext{
*Corresponding author: cajka@vsmvv.cz
} 
With regard to the above, one need to examine initiatives that might be called climate change experiments. Around the world, university-oriented partnerships and experiments to promote urban sustainability are flourishing. Citizens can play an important role, together with governments, businesses, non-governmental organisations and researchers, in making social, technological and policy innovations to achieve sustainability [6[. Some of the greatest challenges of our time, such as population growth, climate change or the use of e-services, are best dealt with in cities [7]. Universities work with various social actors to trigger and drive sustainable change in specific regions, cities and communities with various social actors. Many prestigious universities around the world cross campus boundaries to form ambitious partnerships with industry, government and civil society organizations $[8,9]$. Universities seek to achieve sustainability in this role of co-creation by working with society to create it. The literature on global environmental policy shows that non-state actors (corporations, NGOs, international foundations and community groups) are increasingly involved in the response to climate change [10].

An analysis of governance modes has been developed in relation to community organizations [11, 12]. Although most of the experiments are conducted by local governments, many other actors intervene and conduct experiments through partnerships. Some findings suggest that the area of authority is becoming blurred and that the importance of partnerships with the importance of non-state actors in areas previously considered to be governed by state actors is increasing. Coupled with enabling governance, partnerships emphasize the expansion of local forms of authority to support initiatives by non-state actors. Several data sources outline the various ways in which universities can contribute to sustainability through the joint creation of target brands, initiatives and multi-stakeholder networks [13, 14].

Additionally, university teams should work on projects that tend to facilitate student participation. The relationships between stakeholders and universities need to be studied as they evolve over time. It is crucial to understand how perceptions of the role of universities have changed and to verify the temporal dimension of sustainability.

\section{University collaboration for creating sustainable urban areas}

Universities worldwide engage in environmental research, education and outreach, examining topics that range from the history of environmental activism to the impact of climate change on land and ocean biodiversity [15]. The sustainable cities programmes utilise innovation and energy from students and faculty to generate ideas for critical projects that support progressive sustainable initiatives. The working relationship will allow the talents of to strengthen the university and the community. Forces need to be joined to create local sustainability funds. Many existing examples exist, such as IBM's Smart Cities, EPA and HUD's DOT Partnership for Sustainable Communities, as part of a national urban sustainability innovation and development systems [16]. Research on the issue is small as there are not enough resources to pursue it. Although the consequences of linking growing populations to cities are well known, many state and local leaders in developed and semideveloped countries are unaware of the strategies and resources which can be used to implement sustainable urban development policies. The role of university partnerships in the co-production of knowledge and implementation of urban sustainability experiments in the industrialised and less-developed countries is key [17]. More and more university-oriented partnerships and experiments to promote urban sustainability are flourishing around the world. These remaining needs have to addressed by using training in sustainable urban planning to give cities access to tools, communication networks and improved resources to practice good and sustainable habits. 
Moreover, many high-profile universities have crossed campus boundaries around the world to form ambitious partnerships with industry, government and civil-society organizations [18]. Partnerships such as the aforementioned universities are increasingly recognised as the only viable path to sustainability that addresses several aspects of the complex social, economic, technological, political and cultural fabric around us and mobilizes the necessary institutions, knowledge and resources within a comprehensive framework [19]. As more universities and faculties are encouraged to engage in alliances for the transition to urban sustainability, several obstacles must be overcome. Co-creation is that the role of universities is that they try to achieve sustainable development by working with society to create it. Universities work with diverse social actors to trigger and drive sustainable change in specific regions, cities and communities [20]. Students collaborate with partners to identify existing projects and, of course, propose ideas for real solutions to municipal challenges of sustainable development. The overarching objective is to stimulate and sustain the economy and contribute to the development of productive and liveable communities. This contributes in addition to training and research to the promotion of education in universities to the promotion of education in the community. The partnerships to promote higher education on sustainable urbanization, introduce complex problems and gain perspectives. This might help to bring together a network of scientists, industry leaders and policy partners dedicated to building better cities of the future [21]. The outcome planning will provide a roadmap for future research efforts (including the publication productivity in prestigious journals [22]) and will encourage new collaborations that have not yet been considered. The stages of evaluation and transformation are part of a process built up by conducting interviews and evaluations with project managers.

Various public-private partnerships can be used to develop sustainable and liveable communities while protecting historical, cultural and environmental resources. New sustainable solutions to urban problems include green buildings and apartments, mixed-use development, walkability, green and open spaces, alternative energy sources such as sun and wind and transport options [23].

New sustainable urban development and redevelopment should have a variety of commercial, institutional and educational uses as well as housing in all sizes, styles and prices. Good sustainability planning can help improve the well-being of people and their communities by transforming their urban areas and neighbourhoods into healthy, efficient spaces.

Cities play a crucial role in addressing the environmental challenges that face the world today. The creation of sustainable communities includes physical, economic, political, social and environmental aspects and contains many challenges [24]. For example, social innovation for sustainable cities is best when it aims to promote social innovation, defined as new products, processes, services and business that improve the performance of essential municipal systems (e.g., energy, finance, food, housing, transport) and create measurable social and environmental value [25]. Instead of seeking incremental or continuous (vague) improvements to achieve better results, breakthroughs in social innovation require crosssectoral cooperation and systemic thinking to maximize scale and measurable impact. One needs to examine the emerging field of social innovation in the context of sustainable urban development and explore core concepts, case studies and best practices that are beginning to define the field. This should bring together authors from around the world, will find in-depth discussions on the history, theory, methodology, and practice of local and regional development from a global, national, regional and local perspective. In addition, it should include the elements of demand-driven science, push-back, public procurement, localization and community development theory relevant for urban, regional and sustainable development [26]. 


\section{Academic norms and incentives can hinder sustainability}

Key themes and core concepts for the co-production of knowledge have emerged in the last several years in a number of fields including public administration, science and technology (STS), sustainability and science, all of which have a specific set of concerns and agendas [27]. Knowledge co-production recognizes the decentralized nature of knowledge and knowledge production is organized around interactions between researchers and social actors to foster a common understanding of what is known and what can be done. Knowledge supposedly generated by scientific research is only one form of knowledge distributed among social actors [28]. Despite the explosion of grants to involve citizens in the provision of public services the influence of individual and organizational factors on co-production has hardly been studied [29].

Elinor Ostrom defined in her work on the provision of urban services by police as: "the process by which input factors of individuals are transformed into goods and services not necessarily within the same organisation" [30]. Until now, large-scale quantitative studies examining the determinants of co-productions have focused on how the individual level correlates with citizens' commitment to public service. Our analysis suggests that people with higher self-efficacy and greater involvement in formal groups (caregivers, rural residents, women, university graduates and middle-aged people) are more likely to associate environmental outcomes. These findings suggest that partnerships in the areas of energy, buildings, governance and social systems are developing at local and urban levels and involve cooperation between local and regional governments [31]. While large-scale quantitative studies examining the determinants of $\mathrm{CO} 2$ production can contribute to our understanding of the enablers and barriers of $\mathrm{CO} 2$ production, empirical research is needed that comprises a broader frame of reference to capture the full spectrum of variables shaping the contribution of citizens to the public service [32].

The potential outcomes of university initiatives to help shape and co-produce urban sustainability are not restricted to knowledge and policy. Usability comes from theories of sustainability science and direct engagement with social actors. Collectively this gathered insight forms the basis for a nested conceptual framework within which design can be turned into action in collaboration with sustainability science. For example, transdisciplinary knowledge is crucial to sustain sustainable resource management on the ground, as it supports sustainability research that transcends the traditional dichotomy between objective and subjective viewpoints in science to address complex phenomena that occur at non-equivalent levels of reality [33]. There is ample evidence of the benefits of working with indigenous peoples and their knowledge to manage natural resources, understand social and environmental change and address other sustainability challenges jointly. Many sustainability researchers claim that co-production processes a better match between scientific research and other opportunities to understand the problems and relationships facing decision-makers in order to create innovative and actionable solutions [34]. Recent literature reviews of the role of indigenous and local knowledge in the transformation of sustainability suggest that co-production not only contributes to better descriptions of sustainability but also helps to a more plural understanding of transformation [35]. However, we have pointed out crucial weaknesses in the conceptualization of coproduction in sustainability science, especially with regard to power politics and governance.

Therefore, one needs to provide suggestions on how to address these weaknesses through deep collaboration with the public administration and STS and offer a comprehensive vision for improving the use of design practices beyond reflective "co-production" within sustainability science. The very success of scientific and social studies as a field of basic research tends to make their practical implications invisible to many researchers who use them in their struggle to produce more useful knowledge. Beyond the conceptual view of co- 
design and co-production, it is also about politics, knowledge and politics as way of being. For those who get involved there is a way to deliver a version of sustainability that appeals to a specific group. This requires scientists and stakeholders involved to consider their own positions humbly and reflectively and to accept that their own view of the world, what kind of science and knowledge is appropriate, and which positions are partial [36]. True coproduction processes involve bringing these partisans into the same arena and enabling them explicitly to speak about their partisanship so that one can open debates and convergence where there is real controversy over what needs to be worked out.

It is also fair to support partners at the beginning of a project in order to develop a common vision, agree on a set of outcomes and have a common understanding of what they want to benefit from specific collaborations and how the benefits are shared at the end of the financing. Participants stressed the importance of developing a comprehensive framework that recognizes the social, environmental and economic benefits as well as the intangible benefits of new partnerships, altruism and individual motivations [37]. It was also agreed that knowledge gained through important individual and project partnerships should be shared with an established network of colleagues and practice communities. Communication and shared learning benefits from this approach played a decisive role in the planning and advance transfer of research results from collaborative projects. As a result, new models of science funding that support researchers and users interactively are emerging. Implications for policy include the recognition that targeted funding programmes can play a key role in promoting partnerships [38]. Strategies to improve project management are also needed to ensure that projects take into account conflicting priorities and time horizons of science and local government.

\section{Universities advancing sustainability through the cross-sector collaboration}

Cross-sectoral cooperation and partnerships are an essential part of any strategy to improve the health and well-being in the countries such as the United States. Cross-sectoral cooperation has the potential to align resources and contributions from multiple sectors to address problems [39]. However, there is a lack of research into the types and forms of crosssectoral cooperation that can be used in rural communities to address community problems. In order to address this lack of research investigating the types and forms of cross-sectoral collaborations that rural communities use to address community health challenges, case studies need to be done to demonstrate progress in engaging stakeholders from multiple sectors to create healthier communities.

It becomes clear that rural communities use cross-sectoral cooperation to address community health issues, but that these forms of interaction and research into genuine and lasting partnerships are rare [40]. The development, operation and maintenance of crosssectoral cooperation are influenced by a number of contextual and practical factors. Practical strategies and policy interventions can be used to improve cross-sectoral cooperation in rural communities. Cooperation with bilateral and multilateral development organisations, governments, civil society, academia and other private sectors can help establish new approaches. Partners can take a number of steps to use evidence to drive system change. Measuring results to monitor ongoing progress can provide the evidence needed to drive systemic change. For example, in cross-sectoral cooperation implementation studies assessing the effectiveness of cooperation in can help bring about continuous improvement. Results evaluations, however, assess the results of the partnership for the target community, which can serve as a basis for future work and advocacy. Demonstrating effective solutions leads cross-sectoral partnerships to advocate policies that address systemic inequalities and initiate wider systemic change. 
Many communities increasingly rely on cross-sectoral cooperation as a collective model of action to overcome the complex problems of our education system. These collaborations are linked to national networks that promote cross-program learning and resource sharing and provide national visibility and political leverage. They should focus on the implementation of sustainability and while some of these ideas may prove difficult to develop, the objectives and comments presented here are modest proposals to enhance sustainability through cross-sectoral cooperation. Cooperation in defining the need to combat poverty, identify supply and treatment gaps, develop solutions, develop, monitor and evaluate programmes. Such solutions can be developed in collaboration with the local authorities and stakeholders that can use the available data and repository to capture and combine the impacts of industry initiatives. More than two decades of collaborative participatory research have helped provide knowledge on how to form high-quality collaborative partnerships. Research has identified an increasing number of variables that determine the extent of cooperation between cooperation partners in order to shed light on the determinants of sustained crosssectoral social cooperation. This analysis builds on evidence-based understanding of the sustainability impact of cross-sectoral cooperation on public health. The different sectoral logics inherent in cross-sectoral social cooperation (within this logic, cooperation partners face tensions and opposing forces inherent in collaboration, regardless of means and potential benefits. Such tensions must be overcome and differences must be overcome in order to enable a lasting cross-sectoral social cooperation.

The aim of promoting sustainability at universities is to establish cross-sectoral networks in which not only scientists but also practitioners are involved in order to link sustainability with not only research but also public relations. The stakeholders should be working to improve cross-sectoral cooperation through assessments and measures at the system level to improve health and promote equity and social justice [41]. In order to involve stakeholders, one must clearly define the benefits each partner can expect from working together. One should try to understand the incentives and constraints of the partners and articulate her or his own to ensure that their partnership balances the needs of each to maximize progress toward common goals. Governments often express a desire to create jobs or to improve livelihoods in a particular region or sector of economy [42]. Development and humanitarian organisations often document how the partnership encourages progress towards one or more United Nations' Sustainable Development Goals or specific problems in areas of high need.

\section{Conclusions}

There are many contrasting priorities in academia and local governments. Climate change risks and strategies pose a serious challenge to the utility companies. These companies must make high-level decisions on how to respond to climate change, how much to invest in this response, how to engage in policy debates and how to choose alternative responses. Governments use policies (regulation and taxation) to influence people's behaviour to address environmental problems. For example, the increasing impact of climate change targets on air pollution policy has led to a shift in the regulatory approach to vehicle emissions to the extent that policy measures have been taken which have led to unintended and unlawful levels of air pollution, in particular nitrogen oxides and particulate matter. As such, climate adaptation competes for space in the political agendas and budgets of local governments.

Strategies to improve project management are needed to ensure projects take into account the conflicting priorities and time horizons of science and local government. Implications for policy include evidence that targeted funding programs can play a key role in promoting partnerships. It is an evidence of the development of adaptation policies and initiatives. During natural disasters, rescue efforts can often be hampered by a lack of coordination between emergency services and national services, which was controlled by the state 
government, and active military units controlled by federal agencies. This violated the principle of the unit of command and created opportunities for unwelcome employees to avoid responsibility by pretending to be more involved in projects than other superiors. This has the potential to create confusion among staff as they are unsure who is guiding them and setting priorities for their work. When it comes to the matrix structure of project managers, potential conflicts arise. In this structure the project leader wants to assign the best people in the company to his project and the boss evaluates them based on how well their project performs.

All in all, university collaboration for co-designing sustainable urban areas proves to be very relevant and important. Even though the goals of the local and rural authorities and the universities and institutions of higher education might not coincide, the partnership between the two is a key objective that has to be supported by all available means and should be therefore fostered by the federal and central governments using various political and financial incentives.

\section{References}

1. Z. Chinchilla-Rodríguez, L. Miao, D. Murray, N. Robinson-García, C. Costas, C. Sugimoto, Frontiers in Research Metrics and Analytics, 3, 17 (2018)

2. A. Paletta, F. Fava, F. Ubertini, C. Bastioli, G. Gregori, F. La Camera, A. Douvan, Sustainable Production and Consumption, 19, 1-10 (2019)

3. E. Puerari, T. De Koning, T. Von Wirth, P. Karré, I. Mulder, D. Loorbach, Sustainability, 10(6), 1893 (2018)

4. R. Nureev, V. Volchik, W. Strielkowski, Social Sciences, 9(5), 79 (2020)

5. E. Dasno-Wiredu, M. Sanda, Environment, Space, Place, 13(1), 133-156 (2021)

6. M. Pendras, Y. Dierwechter, Journal of Geography in Higher Education, 36(2), 307-321 (2012)

7. A. Chiabai, S. Platt, W. Strielkowski. Tourism Economics, 20(2), 263-277 (2014)

8. G. Trencher, M. Yarime, A. Kharrazi, Journal of Cleaner Production, 50, 40-55 (2013)

9. J. Herberg, T. Haas, D. Oppold, D. Von Schneidemesser, Sustainability, 12(8), 3278 (2020)

10. H. Bulkeley, Environmental Politics, 30(1-2), 266-284 (2021)

11. V. Žofčinová, M. Barinková, Z. Hrabovská, Public Administration Issues, 6, 133-155 (2020)

12. A. Kronsell, D. Mukhtar-Landgren, European Planning Studies, 26(5), 988-1007 (2018)

13. N. Witjes, P. Olbrich, Science and Public Policy, 44(4), 524-534 (2017)

14. I. Lindsey, T. Chapman, O. Dudfield, International Journal of Sport Policy and Politics, 12(1), 127-146 (2020)

15. M. Monroe, R. Plate, A. Oxarart, A. Bowers, W. Chaves, Environmental Education Research, 25(6), 791-812 (2019)

16. Maxwell, K., Grambsch, A., Kosmal, A., Larson, L., \& Sonti, N. (2018), https://www.fs.usda.gov/treesearch/pubs/57463

17. L. Árva, S. Pásztor, V. Pyatanova, Economy and Finance: English Language Edition of Gazdaság és Pénzügy, 7(1), 56-77 (2020)

18. A. Hsu, J. Brandt, O. Widerberg, S. Chan, A. Weinfurter, Climate Policy, 20(4), 443$457(2020)$ 
19. C. Anderson, J. Bruil, M. Chappell, C. Kiss, M. Pimbert, Sustainability, 11(19), 5272 (2019)

20. W. Purcell, H. Henriksen, J. Spengler, International Journal of Sustainability in Higher Education, 3(3), 203-220 (2019)

21. S. Mehling, N. Kolleck, Sustainability, 11(18), 4982 (2019)

22. W. Strielkowski, Nature, 544(7651), 416 (2017)

23. Z. Allam, D. Jones, Economies, 7(2), 62 (2019)

24. J. Macke, J. Sarate, S. De Atayde Moschen, Journal of Cleaner Production, 239, 118103 (2019)

25. S. Gupta, V. Kumar, E. Karam, Industrial Marketing Management, 89, 499-516 (2020)

26. G. Bristow, A. Healy, Introduction to the handbook on regional economic resilience (2020)

27. S. Bremer, S. Meisch, Wiley Interdisciplinary Reviews: Climate Change, 8(6), e482 (2017)

28. B. Sletto, S. Tabory, K. Strickler, Global Environmental Change, 54, 195-202 (2019)

29. W. Voorberg, V. Bekkers, L. Tummers, Public Management Review, 17(9), 1333-1357 (2015)

30. E. Ostrom, World Development, 24(6), 1073-1087 (1996)

31. B. Evans, M. Joas, S. Sundback, K. Theobald, Governing sustainable cities (2013)

32. T. Bovaird, E. Loeffler, Voluntas: International Journal of Voluntary and Nonprofit Organizations, 23(4), 1119-1138 (2012)

33. D. Manuel-Navarrete, M. Pelling, Global Environmental Change, 35, 558-569 (2015)

34. N. Latulippe, N. Klenk, Current Opinion in Environmental Sustainability, 42, 7-14 (2020)

35. M. Brugnach, H. Ingram, Environmental Science \& Policy, 15(1), 60-71 (2012)

36. S. Van der Hel, Global Environmental Change, 52, 248-258 (2018)

37. W. Strielkowski, E. Volkova, I. Pushkareva, D. Streimikiene, Energies, 12(7), 1392 (2019)

38. J. Arnott, C. Kirchhoff, R. Meyer, A. Meadow, A. Bednarek, Current Opinion in Environmental Sustainability, 42, 38-44 (2020)

39. F. McGuire, L. Vijayasingham, A. Vassall, R. Small, D. Webb, T. Guthrie, M. Remme, Globalization and Health, 15(1), 1-18 (2019)

40. A. Lawrence, J. Wong, S. Molteno, Forest Policy and Economics, 118, 102221 (2020)

41. S. Valencia, D. Simon, S. Croese, J. Nordqvist, M. Oloko, T. Sharma, N. Buck, I. Versace, International Journal of Urban Sustainable Development, 11(1), 4-23 (2019)

42. M. Szostak, Ł. Sułkowski, Creativity Studies, 13(2), 351-368 (2020) 